\title{
The Apolipoprotein $\epsilon 4$ Allele Confers Additional Risk in Children with Familial Hypercholesterolemia
}

\author{
ALBERT WIEGMAN, ERIC J.G. SIJBRANDS, JESSICA RODENBURG, JOEP C. DEFESCHE, \\ SASKIA DE JONGH, HENK D. BAKKER, AND JOHN J.P. KASTELEIN
}

\begin{abstract}
Emma Children's Hospital/Academic Medical Centre [A.W., S.d.J., H.D.B.], Department of Vascular Medicine, Academic Medical Centre [J.R., J.C.D., J.J.P.K.], University of Amsterdam, the Netherlands; Department of Internal Medicine, Metabolic Unit, Erasmus Medical Centre, Rotterdam, the Netherlands [E.J.G.S.]
\end{abstract}

\section{ABSTRACT}

Children with familial hypercholesterolemia (FH) exhibit substantial variance of LDL cholesterol. In previous studies, family members of children with FH were included, which may have influenced results. To avoid such bias, we studied phenotype in 450 unrelated children with $\mathrm{FH}$ and in 154 affected sib-pairs. In known families with classical FH, diagnosis was based on plasma LDL cholesterol above the age- and genderspecific 95th percentile. Girls had $0.47 \pm 0.15 \mathrm{mmol} / \mathrm{L}$ higher LDL cholesterol, compared with boys $(p=0.002)$. Also in girls, HDL cholesterol increased by $0.07 \pm 0.03 \mathrm{mmol} / \mathrm{L}$ per $5 \mathrm{y}$ ( $p_{\text {for }}$ trend $=0.005)$; this age effect was not observed in boys. The distribution of apolipoprotein (apo) E genotypes was not significantly different between probands, their paired affected siblings, or a Dutch control population. Carriers with or without one $\epsilon 4$ allele had similar LDL and HDL cholesterol levels. Within the affected sib-pairs, the $\epsilon 4$ allele explained $72.4 \%$ of the variance of HDL cholesterol levels $(-0.15 \mathrm{mmol} / \mathrm{L}, 95 \%$ confidence interval -0.24 to $-0.05, p=0.003$ ). The effect of apoE4 on HDL cholesterol differed with an analysis based on probands or on affected sib-pairs. The affected sib-pair model used adjustment for shared environment, type of LDL receptor gene mutation, and a proportion of additional genetic factors and may, therefore, be more accurate in estimating effects of risk factors on complex traits. We conclude that the $\epsilon 4$ allele was associated with lower HDL cholesterol levels in an affected sib-pair analysis, which strongly suggests that apoE4 influences HDL cholesterol levels in FH children. Moreover, the strong association suggests that apoE4 carries an additional disadvantage for $\mathrm{FH}$ children. (Pediatr Res 53: 1008-1012, 2003)
apo, apolipoprotein
BMI, body mass index
FH, familial hypercholesterolemia

\section{Abbreviations}

FH is an autosomal dominant disorder, strongly predisposing for premature coronary disease (1). In the Netherlands, heterozygous $\mathrm{FH}$ has a prevalence of approximately one in 400 individuals, making it one of the most common inherited disorders of metabolism (2). Inherited defects in the gene coding for the LDL receptor constitute the molecular basis for FH (3). As a result, LDL cholesterol is insufficiently taken up by its receptor and, subsequently, plasma LDL cholesterol levels are elevated (3).

In most FH patients, there is excessive deposition of cholesterol esters in the intima of the vasculature, leading to accelerated atherosclerosis and premature coronary artery disease. Although the clinical sequelae of atherosclerosis usually

Received October 11, 2001; accepted December 3, 2002.

Correspondence: A. Wiegman, M.D., Academic Medical Centre, University of Amsterdam, Meibergdreef 9, 1105 AZ Amsterdam, the Netherlands; e-mail: a.wiegman@amc.uva.nl

Supported by Grant 2000D039 from the Netherlands Heart Foundation (J.K.).

DOI: 10.1203/01.PDR.0000064580.23308.CB ensue in adult life, atherogenesis begins in early childhood. A significant positive correlation exists in childhood between serum LDL cholesterol and the extent of atherosclerosis in the coronary arteries and the aorta (4). Moreover, in adolescence, a strong relationship is observed between elevated cholesterol levels and the risk of subsequent coronary disease later in life (5).

However, among children with $\mathrm{FH}$, a substantial variation in LDL cholesterol levels exists and was reported to be associated with age, gender, BMI, diet, and apoE phenotype (6). This suggests that the clinical phenotype in FH children may be influenced by a host of environmental and genetic factors.

Polymorphisms at the apoE locus are among the major factors affecting the variability of serum lipid levels in normal populations (7). Three common alleles, $\epsilon 2, \epsilon 3$, and $\epsilon 4$, code for three protein isoforms, apoE2, E3, and E4, resulting in six major phenotypes (8-10). The $\epsilon 4$ allele is associated with high, and the $\epsilon 2$ allele with lower total and LDL cholesterol levels (11-19). Furthermore, the $\epsilon 2$ allele has been associated with decreased cholesterol absorption (20), which then leads to 
increased cholesterol synthesis and up-regulation of the LDL receptor proteins $(21,22)$. Therefore, variation at the apoE gene locus influences LDL cholesterol metabolism and has been suggested to account for as much as $14 \%$ of the genetically determined variation in total serum cholesterol $(7,23)$.

However, in most previous studies in FH children, siblings were included and this selection on familial factors may have biased the analyses of the influences of additional factors. Therefore, we studied the clinical and biochemical phenotype in strictly unrelated FH children and in affected sib-pairs to estimate the contribution of age, gender, BMI, and apoE genotype to LDL and HDL cholesterol levels in these subjects. Here we report the results of our studies.

\section{METHODS}

Patients. A total of 450 children, 206 boys and 244 girls, were recruited from unrelated consecutive families. The $\mathrm{FH}$ parents had presented with the classical symptoms of $\mathrm{FH}$ (fasting plasma LDL cholesterol $>4.9 \mathrm{mmol} / \mathrm{L}$, and a personal or family history of tendon xanthomas and/or premature coronary artery disease) (24). In addition to vertical transmission from the FH parent, the diagnostic criteria in the children were based on fasting plasma LDL cholesterol above the age- and gender-specific 95 th percentiles $(25,26)$. At present, the diagnosis of FH could be confirmed by molecular methods in $84 \%$ of the 450 unrelated probands. Sixty-nine different types of mutation were found in these 378 children [61 (16\%) carried the frequent Dutch mutation $\mathrm{N} 543 \mathrm{H}+2393 \mathrm{del}$, and $58(15 \%)$ carried another frequent Dutch mutation, $1359-1(\mathrm{G} \rightarrow \mathrm{A})]$. Children homozygous for FH were excluded. None of the children had diabetes mellitus, kidney, liver, or thyroid disease. At the time of sampling, the children did not use any medication known to influence lipid metabolism, except 13 girls who used oral contraceptives.

The study protocol was approved by the Institutional Review Board of the Academic Medical Center. DNA analysis was performed after informed consent was obtained.

Affected sib-pairs. Data were available for affected siblings (a brother or sister) of 154 index children. Out of the affected siblings of one particular family, we selected the second child that visited our outpatient Pediatric Lipid Clinic or by a random method (random numbers table) when more siblings visited the clinic together. The analyses were performed on the index child and one affected sibling only (154 concordant pairs). In 146 (95\%) sib-pairs an LDL receptor gene defect could be demonstrated. In affected sib-pair analyses, the relatives were matched for the specific mutation in the LDL receptor gene, generation, and familial or environmental factors. In a matched multiple linear regression model, the effect of the $\epsilon 4$ allele on the mean concentration of LDL and HDL cholesterol was estimated after adjustment for the difference in age, gender, and BMI within each affected sib-pair.

Controls. A control population of 2018 randomly selected $35-y$-old Dutch males was used for comparison of the apoE allele frequencies. This group has been described in detail elsewhere (27).
Biochemistry. Blood samples were collected after at least a $12 \mathrm{~h}$ overnight fast. Plasma levels of cholesterol and triglycerides were determined by standardized enzymatic procedures (Roche Molecular Biochemicals, Mannheim, Germany) and HDL cholesterol in serum was measured by an automated method using polyethylene-glycol-modified enzymes and sulfated $\alpha$-cyclodextrin (P-800 clinical chemistry analyzer, Roche Diagnostics, Basel, Switzerland) (28). LDL cholesterol levels were calculated using the Friedewald equation (29).

ApoA1 and apoB concentrations were assayed by an immuno-rate-nephelometric procedure using a polyclonal goatanti-human antiserum and were calibrated on World Health Organization-proposed international reference samples (30, 31). ApoE genotypes were identified by characteristic visible bands after amplification by PCR, restriction endonuclease digestion, and electrophoresis on 5\% agarose gel, as described before (32).

Statistical analyses. The statistical analyses were performed by using SPSSWIN 10.0 (SPSS Inc., Chicago, IL, U.S.A.). Chi-square statistics were applied to test for Hardy-Weinberg equilibrium and to compare the apoE allele frequencies of the FH children with the Dutch control population. Lipoprotein levels are presented as mean \pm SEM in millimole per liter. The effects of age, gender, BMI, and apoE allele on the lipid profile were estimated simultaneously in a multiple linear regression analyses.

These effects were also estimated in affected sib-pairs by using a matched multiple linear regression model. The effects of differences in age, gender, BMI, and apoE allele on the differences in lipoprotein levels within the pairs were estimated simultaneously. These differences in age, gender, BMI, and apoE allele were not mutually related and were included concomitantly into the regression analyses. The determinant gender was scored: -1 when the index was a girl and the sibling a boy (38 pairs), 0 (identical gender, 84 pairs), or 1 (index a boy and sibling a girl, 32 pairs). In this way, adjustment for the exact differences in gender within the pairs was made.

\section{RESULTS}

General characteristics. A total of 450 consecutive, unrelated children with $\mathrm{FH}$ were recruited from one outpatient pediatric lipid clinic. The 206 boys and 244 girls had a mean age of $10.8 \mathrm{y}$ [for boys, median age, $10.8 \mathrm{y}$ (range, 2.0-18.7 y); for girls, median age, $10.6 \mathrm{y}$ (range, 3.0-18.2 y); $p=1.0]$. Twenty-seven children $(6 \%)$ had already started smoking before their first visit. The girls had a mean BMI ( \pm SEM) of $18.7 \pm 0.3 \mathrm{~kg} / \mathrm{m}^{2}$ (median BMI, $17.9 \mathrm{~kg} / \mathrm{m}^{2}$; range, $12.6-41.1$ $\mathrm{kg} / \mathrm{m}^{2}$ ) and the boys of $18.3 \pm 0.2 \mathrm{~kg} / \mathrm{m}^{2}$ (median, $17.5 \mathrm{~kg} / \mathrm{m}^{2}$; range, $\left.13.1-30.2 \mathrm{~kg} / \mathrm{m}^{2}\right)(p=0.2)$. Twenty-four children $(5.5 \%)$ had palpable xanthomas. In 81 out of 244 girls $(33 \%)$ menarche had occurred and 13 of them were using oral contraceptives.

Lipoproteins in 450 unrelated probands. Girls had a significantly higher plasma LDL cholesterol $(5.99 \pm 0.10 \mathrm{mmol} / \mathrm{L})$ compared with boys $(5.54 \pm 0.10 \mathrm{mmol} / \mathrm{L}, p=0.002)$. This difference did not change after adjustment for age and carrier 
Table 1. ApoE genotype and $\varepsilon$ allele frequencies

\begin{tabular}{|c|c|c|c|}
\hline Genotype & $\begin{array}{l}\text { FH children } \\
(n=450)\end{array}$ & $\begin{array}{l}\text { Dutch controls } \\
(n=2018)\end{array}$ & $\begin{array}{c}p \\
\text { Value }\end{array}$ \\
\hline E4E4 & 12 & 59 & \multirow{6}{*}{ NS } \\
\hline E4E3 & 135 & 512 & \\
\hline E4E2 & 10 & 45 & \\
\hline E3E3 & 243 & 1128 & \\
\hline E3E2 & 50 & 261 & \\
\hline E2E2 & 0 & $13)$ & \\
\hline Allele & Frequency & Frequency & \multirow[t]{2}{*}{$p$ Value } \\
\hline$\varepsilon 2$ & 0.067 & 0.082 & \\
\hline$\varepsilon 3$ & 0.746 & $0.750\}$ & \multirow[t]{2}{*}{ NS } \\
\hline$\varepsilon 4$ & 0.188 & 0.167 ) & \\
\hline
\end{tabular}

status of at least one $\epsilon 4$ allele $(0.47 \pm 0.15 \mathrm{mmol} / \mathrm{L}, p=$ 0.002). Even considering the wide range of ages among the unrelated children, we did not observe any influence of age on LDL cholesterol levels with or without adjustment for gender and $\epsilon 4$ carrier status $\left(-0.05 \pm 0.10 \mathrm{mmol} / \mathrm{L}\right.$ per $5 \mathrm{y}, p_{\text {for trend }}$ $=0.6)$. BMI and age were correlated $\left(r_{\text {partial }}=0.57, p<\right.$ 0.001 ) and had in similar models comparable effects on LDL cholesterol levels (data not shown).

The levels of HDL cholesterol were similar in boys and girls (both were $1.25 \pm 0.02 \mathrm{mmol} / \mathrm{L} ; p=1.0$ ). In the entire group of children, the mean HDL cholesterol level showed no tendency over age $\left(0.03 \pm 0.02 \mathrm{mmol} / \mathrm{L}\right.$ per $\left.5 \mathrm{y}, p_{\text {for trend }}=0.1\right)$. We repeated this analysis in boys and girls separately. In girls, HDL cholesterol increased with $0.07 \pm 0.03 \mathrm{mmol} / \mathrm{L}$ per $5 \mathrm{y}$ $\left(p_{\text {for }}=0.005\right)$, whereas such an effect of age was not observed in boys. In a multiple regression model, menarche, oral contraceptives, and smoking did not explain the variation of HDL cholesterol in girls. An association was observed between triglyceride and HDL cholesterol levels, as expected. Additional adjustment for the triglyceride concentration did not change the results of the multivariate analyses.

No differences were observed in apoE genotype distribution $\left(\chi^{2}=7.198, d f=5 ; p=0.2\right)$ or allele frequencies $\left(\chi^{2}=4.091\right.$, $d f=2 ; p=0.1)$ between the children and a sample of 2018 Dutch males (Table 1). The results were similar after exclusion of the 13 apoE2 homozygotes from the Dutch control group. ApoE genotypes of the children and control subjects were in Hardy-Weinberg equilibrium $\left(\chi^{2}<4.551, d f=3 ; p>0.2\right)$. Carriers of the different apoE genotypes had similar fasting serum LDL cholesterol levels as shown in Table 2. Moreover, the carriers of an $\epsilon 4$ allele had similar LDL and HDL cholesterol levels to those of the carriers of other alleles (Table 2A). Adjustment for age, gender, and BMI did not change these results (data not shown).

ApoAI and apoB100 levels were available in 391 of the 450 unrelated children with $\mathrm{FH}$. In Table $2 B$, the concentrations are shown according to apoE genotype and the presence of an $\epsilon 4$ allele. The apoB levels were lower in $\epsilon 2$ allele carriers. After exclusion of the $\epsilon 4 \epsilon 2$ carriers, the children with $\epsilon 4$ alleles had similar apoB levels compared with the children without $\epsilon 4$ alleles.

Lipoproteins in 154 affected sib-pairs. The contribution of the $\epsilon 4$ allele to the variation of LDL and HDL cholesterol levels within the affected sib-pairs was estimated using a matched multiple linear regression model with adjustment for the differences in age or BMI, and gender. Because the affected siblings shared environment and an identical mutation in the LDL receptor gene with their probands, additional genetic factors are likely to explain the difference in LDL cholesterol levels. The presence of the $\epsilon 4$ allele did not contribute to the observed differences in LDL cholesterol levels (mean difference $0.16 \mathrm{mmol} / \mathrm{L} ; 95 \% \mathrm{CI},-0.33$ to $0.64 \mathrm{mmol} / \mathrm{L} ; p=0.2$ ) within the affected pairs. The finding that apoB levels were lower in probands with an $\epsilon 2$ allele could not be confirmed in the sib-pairs $(-0.17 \pm 0.12 \mathrm{~g} / \mathrm{L}, p=0.2)$, which supports our findings on LDL cholesterol levels. In the sib-pair analysis, we also did not find an effect of the presence of an $\epsilon 4$ allele on apoB levels $(0.003 \pm 0.01 \mathrm{~g} / \mathrm{L}, p>0.9)$.

Table 2A. Mean serum LDL- and HDL-cholesterol concentrations of 450 unrelated FH children according to apoE genotype or the presence of the $\varepsilon 4$ allele

\begin{tabular}{ccccccc}
\hline & E4E4 $(n=12)$ & E4E3 $(n=135)$ & E4E2 $(n=10)$ & E3E3 $(n=243)$ & E3E2 $(n=50)$ & $p$ Value \\
\hline LDL (mmol/L) & $5.17 \pm 0.36$ & $5.88 \pm 0.12$ & $5.40 \pm 0.28$ & $5.84 \pm 0.10$ & $5.47 \pm 0.23$ & 0.2 \\
HDL (mmol/L) & $1.31 \pm 0.08$ & $1.25 \pm 0.03$ & $1.21 \pm 0.08$ & $1.25 \pm 0.02$ & $1.27 \pm 0.03$ & 0.9 \\
\hline & $\varepsilon 4(n=147)$ & non $\varepsilon 4(n=293)$ & $p$ Value \\
\hline LDL (mmol/L) & & $5.87 \pm 0.12$ & $5.78 \pm 0.09$ & 0.8 \\
HDL (mmol/L) & & $1.25 \pm 0.02$ & $1.25 \pm 0.02$ & 1.0 \\
\hline
\end{tabular}

Values are unadjusted mean serum concentrations \pm SEM; patients with the apo E4E2 genotype $(n=10)$ were excluded from the analyses.

Table 2B. Mean serum apolipoprotein AI and B100 concentrations of 391 of the $450 \mathrm{FH}$ children according to apoE genotype or the presence of the $\varepsilon 4$ allele

\begin{tabular}{|c|c|c|c|c|c|c|}
\hline & E4E4 $(n=10)$ & E4E3 $(n=114)$ & $\mathrm{E} 4 \mathrm{E} 2(n=9)$ & E3E3 $(n=213)$ & $\mathrm{E} 3 \mathrm{E} 2(n=45)$ & $p$ Value \\
\hline apoA (g/L) & $1.24 \pm 0.05$ & $1.27 \pm 0.02$ & $1.30 \pm 0.06$ & $1.27 \pm 0.02$ & $1.32 \pm 0.03$ & 0.7 \\
\hline apoB $(g / L)$ & $1.54 \pm 0.10$ & $1.70 \pm 0.03$ & $1.39 \pm 0.07$ & $1.64 \pm 0.03$ & $1.50 \pm 0.06$ & 0.02 \\
\hline apoA (g/L) & & $1.27 \pm 0.02$ & & $1.28 \pm 0.01$ & & 0.6 \\
\hline apoB (g/L) & & $1.68 \pm 0.03$ & & $1.62 \pm 0.03$ & & 0.1 \\
\hline
\end{tabular}

Values are unadjusted mean serum concentrations \pm SEM; patients with the apo E4E2 genotype $(n=9)$ were excluded from the analyses. 
Table 3. Variance of mean paired differences in HDL-cholesterol levels as explained by specific determinants

\begin{tabular}{lcrc}
\hline Determinant & HDL difference & $\%$ & $p$ Value \\
\hline$\varepsilon 4$ allele & $-0.15(-0.24$ to -0.05$)$ & 72.4 & 0.003 \\
Age & $-0.01(-0.03$ to -0.002$)$ & 7.2 & 0.02 \\
Gender & $-0.03(-0.10$ to 0.04$)$ & 14.7 & NS \\
Unexplained & $0.01(-0.04$ to 0.06$)$ & 5.7 & NS \\
\hline
\end{tabular}

Values for HDL cholesterol are given as means in millimole per liter with $95 \%$ confidence interval in parentheses (The negative value of the difference in HDL cholesterol as a result of differences in $\varepsilon 4$ carrier status within the pairs is the result of a larger number of relatives with the $\varepsilon 4$ allele compared with the probands.)

Strikingly, the presence of the $\epsilon 4$ allele explained $72.4 \%$ of the variance in HDL cholesterol levels $(-0.15 \mathrm{mmol} / \mathrm{L} ; 95 \%$ CI, -0.24 to $-0.05 ; p=0.003$ ) (Table 3 ). In a similar model with identical results, differences in BMI significantly explained $14.5 \%$ of the variation of the mean paired differences in HDL cholesterol levels. Part of this may be attributed to an effect of differences in age, because the differences in age and BMI were correlated $\left(r_{\text {partial }}=0.59 ; p<0.001\right)$. In agreement with our findings on HDL cholesterol levels, the $\epsilon 4$ allele was associated with lower apoAI concentrations among the sibpairs $(-0.12 \pm 0.04 \mathrm{~g} / \mathrm{L}, p=0.002)$.

The distribution of the apoE genotypes was not significantly different between the probands, their paired affected siblings, and the Dutch control population. Nonetheless, the affected siblings were not in Hardy-Weinberg equilibrium, illustrating the dependency of this second sample coming from the same families $\left(\chi^{2}=8.365, d f=3 ; p=0.04\right)$.

\section{DISCUSSION}

We studied a large cohort of unrelated FH children with a wide age range and no concomitant disorders. The apoE genotype distribution and allele frequencies of our cohort did not differ from the general Dutch population and were in HardyWeinberg equilibrium (27). With these conditions met, it became possible to assess the impact of the apoE genotype on lipids and lipoproteins in these children.

In a wide range of populations, both adults and children, it has been convincingly demonstrated that the $\epsilon 4$ allele is associated with both increased LDL cholesterol and apoB, whereas the opposite is true for the $\epsilon 2$ allele $(27,33-38)$.

We could not, however, demonstrate a statistically significant effect of the $\epsilon 4$ allele on LDL cholesterol, HDL cholesterol, or triglycerides in our carefully recruited and unrelated pediatric FH cohort. Only the apoB levels were lower in $\epsilon 2$ allele carriers.

Our observations in these FH children suggest that the apoE genotypes have little influence on their lipid profiles. This is in contrast with normocholesterolemic children, whose $\epsilon 4$ alleles are associated with increased levels of LDL cholesterol (3941). The variation of LDL cholesterol levels in healthy individuals is to a certain extent determined by the affinity of the different apoE isoforms for the LDL receptor. It is likely that in heterozygous $\mathrm{FH}$, with $50 \%$ of LDL receptor activity, and LDL cholesterol levels twice the normal value, the subtle effects of apoE isoforms are nullified. A similar effect is seen with variation in other genes affecting LDL cholesterol levels, such as cholesteryl ester transfer protein and microsomal triglyceride transfer protein (42). At young age, the presence of a LDL receptor gene mutation likely overrules other factors and influences the variation of LDL cholesterol levels in terms of a major gene. Our findings are similar to those in adults with $\mathrm{FH}$, in whom the apoE phenotype has no influence on the lipid profile $(43,44)$. In adults, the type of mutation in the LDL receptor gene contributes to the variation of LDL and HDL cholesterol levels; moreover, it determines to a large extent the occurrence of tendon xanthomas (45). In our series of unrelated FH children, such mutation-related effects may have diminished the possibilities to quantify the contribution of the apoE genotype.

Besides these LDL locus effects, environmental factors may also contribute to the variation of the lipid profiles in $\mathrm{FH}$ children similar to normocholesterolemic children (39). Therefore, we also performed analyses in pairs of affected siblings. All affected siblings shared their environment and carried an identical mutation in the LDL receptor gene. As a result of matching these relatives, the effect of additional genetic factors to the variation of LDL and HDL cholesterol levels can be estimated independent of environment and type of LDL receptor gene mutation. In this model, the $\epsilon 4$ allele did not explain variation of the LDL cholesterol levels, nor could the finding of lower apoB levels in $\epsilon 2$ allele carriers be confirmed in the sib-pairs. However, carriers of an $\epsilon 4$ allele had lower HDL cholesterol levels and this allele explained $>50 \%$ of the difference in HDL cholesterol levels within the affected pairs. The effect of the $\epsilon 4$ allele on HDL cholesterol has therefore been underestimated in our series of unrelated children. This is probably a consequence of the contribution of the type of LDL receptor gene mutation to the variation of the HDL trait (45). In adults with $\mathrm{FH}$, low HDL cholesterol levels associate with coronary artery disease (46). An $\epsilon 4$ allele may therefore confer a serious disadvantage for $\mathrm{FH}$ children.

Moreover, a recent intriguing study showed that an $\epsilon 4$ allele may have an untoward effect in survivors of myocardial infarction independent of lipoprotein levels (47).

The strength of the present study is that the influence of the $\epsilon 4$ allele on the lipid profile was analyzed in both a series of probands and affected sib-pairs. As explained above, earlier studies contained both probands and relatives and, therefore, the findings may have been influenced by familial factors. These familial factors could consist of the mutation type in the LDL receptor gene, additional genetic factors, and environmental factors. Our analysis of a series of probands was relatively independent of such additional familial factors compared with the earlier studies. However, similar to these earlier studies, it may be biased by the type of mutation in the LDL receptor gene. The analysis of the affected sib-pairs avoids such bias by matching for the haplotype of the LDL receptor locus. In addition to matching based on the molecular defect in the LDL receptor locus, this analysis also adjusts for shared environment and shared genome. In the matched regression model, we further adjusted for differences in age, gender, and BMI to reduce the variance within the matched pairs caused by other sources than the apoE locus. The combination of analy- 
ses, in the present study, shows that the analysis of index cases is relatively insensitive to the influences of the apoE locus, whereas the affected sib-pair analysis allowed us to detect a remarkable lower concentration of HDL cholesterol in carriers of the $\epsilon 4$ allele compared with other alleles. Additional adjustment for differences in triglyceride levels did not change the results. In agreement with our findings on HDL levels, the $\epsilon 4$ allele was associated with lower apoAI levels among the sib-pairs.

In conclusion, the $\epsilon 4$ allele did not cause variance of fasting LDL cholesterol level in children with FH. The carriers of this allele had significantly lower HDL cholesterol levels compared with the carriers of the other alleles. These effects were studied free from influences of the mutation type in the LDL receptor gene and other familial factors.

\section{REFERENCES}

1. Goldstein JL, Hobbs HH, Brown MS 2001 Familial hypercholesterolemia. In: Scriver CR, Beaudet AL, Sly WS, Valle D (eds) The Metabolic and Molecular Bases of Inherited Disease, 8th Ed. McGraw-Hill, New York, pp 2863-2913

2. Lansberg PJ, Tuzgöl S, Ree MA vd, Defesche JC, Kastelein JJP 2000 Higher prevalence of familiar hypercholesterolemia than expected in adult patients of four family practices in Netherlands [in Dutch]. Ned Tijdschr Geneeskd 144:1437-1441

3. Brown MS, Goldstein JL 1986 A receptor-mediated pathway for cholesterol homeostasis. Science 232:34-47

4. Newman III WP, Freedman DS, Voors AW, Gard PD, Srinivasan SR, Cresanta JL, Williamson GD, Webber LS, Berenson GS 1986 Relation of serum lipoprotein levels and systolic blood pressure to early atherosclerosis. The Bogalusa Heart Study. N Engl J Med 314:138-144

5. Neaton JD, Wentworth D, for the Multiple Risk Factor Intervention Trial Research Group 1992 Serum cholesterol, blood pressure, cigarette smoking, and death from coronary heart disease. Overall findings and differences by age for 316,099 white men. Arch Intern Med 152:56-64

6. Tonstad S, Leren TP, Sivertsen M, Ose L 1995 Determinants of lipid levels among children with heterozygous familial hypercholesterolemia in Norway. Arterioscler Thromb Vasc Biol 15:1009-1014

7. Davignon J, Gregg RE, Sing CF 1988 Apolipoprotein E polymorphism and atherosclerosis. Arteriosclerosis 8:1-21

8. Zannis VI, Breslow JL 1981 Human very low density apolipoprotein E isoprotein polymorphism is explained by genetic variation and post-translational modification. Biochemistry 20:1033-1041

9. Uterman G, Steinmetz A, Weber W 1982 Genetic control of human apolipoprotein E polymorphism: comparison of one- and two-dimensional techniques of isoprotein analysis. Hum Genet 60:344-351

10. Rall Jr SC, Mahley RW 1992 The role of apolipoprotein E genetic variants in lipoprotein disorders. J Intern Med 231:653-659

11. Uterman G, Pruin N, Steinmetz A 1979 Polymorphism of apolipoprotein E: effect of a single polymorphic gene locus on plasma lipid levels in man. Clin Genet 15:63-72

12. Wardell MR, Suckling PA, Janus ED 1982 Genetic variation in human apolipoprotein E. J Lipid Res 23:1174-1182

13. Bouthillier D, Sing CF, Davignon J 1983 Apolipoprotein E phenotyping with a single gel methods: application to the study of informative mating. J Lipid Res 24:10601069

14. Menzel H-J, Kladetzky R-G, Assman G 1983 Apolipoprotein E polymorphism and coronary artery disease. Arteriosclerosis 3:310-315

15. Robertson FW, Cumming AM 1985 Effects of apolipoprotein E polymorphism on serum lipoprotein concentration. Arteriosclerosis 5:283-292

16. Sing CF, Davignon J 1985 Role of the apolipoprotein E polymorphism in determining normal plasma lipid and lipoprotein variation. Am J Hum Genet 37:268-285

17. Ehnholm C, Lukka M, Kuusi T, Nikkila E, Utermann G 1986 Apolipoprotein E polymorphism in the Finnish population: gene frequencies and relation to lipoprotein concentrations. J Lipid Res 27:227-235

18. Eto M, Watanabe K, Ishii K 1986 Reciprocal effects of apolipoprotein $\epsilon$ alleles $(\epsilon 2$ and $\epsilon 4)$ on plasma lipid levels in normolipidemic subjects. Clin Genet 29:477-484

19. Boerwinkle E, Utermann G 1988 Simultaneous effects of the apolipoprotein E polymorphism on apolipoprotein E, apolipoprotein B and cholesterol metabolism. Am J Hum Genet 42:104-112

20. Kesäniemi YA, Ehnholm C, Miettinen TA 1987 Intestinal cholesterol absorption efficiency in man is related to apoprotein E phenotype. J Clin Invest 80:578-581

21. Angelin B, Holmquist L, Leijd B, Einarsson K 1990 Bile acid metabolism in familia dysbetalipoproteinaemia: studies in subjects with the apolipoprotein E2/2 phenotype. Eur J Clin Invest 20:143-149
22. Kesäniemi YA, Ehnholm C, Miettinen TA 1987 Within-population variation of serum cholesterol, apolipoprotein E phenotype and intestinal cholesterol absorption efficiency. Circulation 76(suppl IV):395

23. Demant T, Bedford D, Packard CJ, Shepherd J 1991 Influence of apolipoprotein E polymorphism on apolipoprotein B-100 metabolism in normolipidemic subjects. J Clin Invest 88:1490-1501

24. Tonstad S 1997 Familial hypercholesterolemia: how to identify children with FH. J Norwegian Soc Cardiol 10(suppl 3):32-37

25. National Cholesterol Education Program 1992 Report of the expert panel on blood cholesterol levels in children and adolescents. Pediatrics 89(suppl):525-584

26. Hickman TB, Briefel RR, Carroll MD, Rifkind BM, Cleeman JI, Maurer KR, Johnson CL 1998 Distributions and trends of serum lipid levels among United States children and adolescents ages 4-19 years: data from the third National Health and Nutrition Examination Survey. Prev Med 27:879-890

27. Smit M, Knijff P de, Rosseneu M, Bury J, Klasen E, Frants R, Havekes L 1988 Apolipoprotein E polymorphism in the Netherlands and its effect on plasma lipid and apolipoprotein levels. Hum Genet 80:287-292

28. Sugiuchi H, Uji Y, Okabe H, Irie T, Uekama K, Kayahara N, Miyauchi K 1995 Direct measurement of high-density lipoprotein cholesterol in serum with polyethylene glycol-modified enzymes and sulfated $\alpha$-cyclodextrin. Clin Chem 41:717-723

29. Friedewald WT, Levy RJ, Frederickson DS 1972 Estimation of the concentration of low-density lipoprotein cholesterol in plasma, without use of preparative ultracentrifuge. Clin Chem 18:499-502

30. Cheung MC, Albers JJ 1977 The measurement of apolipoprotein A-I and A-II levels in men and women by immunoassay. J Clin Invest 60:43-50

31. Albers JJ, Cabana VG, Hazzard WR 1975 Immunoassay of human plasma apolipoprotein B. Metabolism 24:1339-1351

32. Reymer PWA, Groenemeijer BE, Burg R v.d., Kastelein JJP 1995 Apolipoprotein E genotyping on agarose gels. Clin Chem 41:1046-1047

33. Yanagi H, Shimakura Y, Yamanouchi Y, Watanabe Y, Tsuchiya S, Hamaguchi H 1990 Association of hypercholesterolemia and apolipoprotein E4 in school children. Clin Genet 38:264-269

34. Hallman DM, Boerwinkle E, Saha N, Sandholzer C, Menzel HJ, Csazar A, Utermann G 1991 The apolipoprotein E polymorphism: a comparison of allele frequencies and effects in nine populations. Am J Hum Genet 49:338-349

35. Xu CF, Talmud PJ, Angelico F, Ben MD, Savill J, Humphries SE 1991 Apolipoprotein E polymorphism and plasma lipid, lipoprotein and apolipoprotein levels in Italian children. Genet Epidemiol 8:389-398

36. Bercedo-Sanz A, Gonzalez-Lamuno D, Malaga S, Garcia-Fuentes M 1999 Impact of apo $\epsilon 4$ allele on total cholesterol levels of children in northern Spain. Clin Genet 55:69-70

37. Mahley RW, Huang Y 1999 Apolipoprotein E: from atherosclerosis to Alzheimer's disease and beyond. Curr Opin Lipidol 10:207-217

38. Isasi CR, Shea S, Deckelbaum RJ, Couch SC, Starc TJ, Otvos JD, Berglund L 2000 Apolipoprotein $\epsilon 2$ allele is associated with an anti-atherogenic lipoprotein profile in children: the Columbia University BioMarkers Study. Pediatrics 106:568-575

39. Kallio MJT, Salmenperä L, Siimes MA, Perheentupa J, Gylling H, Miettinen TA 1997 Apolipoprotein E phenotype determines serum cholesterol in infants during both high-cholesterol breast feeding and low-cholesterol formula feeding. J Lipid Res 38:759-764

40. Kallio MJT, Salmenperä L, Siimes MA, Perheentupa J, Gylling H, Miettinen TA 1998 The apolipoprotein E phenotype has a strong influence on tracking of serum cholesterol and lipoprotein levels in children: a follow-up study from birth to the age of 11 years. Pediatr Res 43:381-385

41. Srinivasan SR, Ehnholm C, Elkasabany A, Berenson G 1999 Influence of apolipoprotein E polymorphism on serum lipids and lipoprotein changes from childhood to adulthood: the Bogalusa Heart Study. Atherosclerosis 143:435-443

42. Defesche JC, Sauvage Nolting PWR de, Kastelein JJP 2000 Familial hypercholesterolemia: factors affecting phenotypic expression. In: Stenne S, Olson AG (eds) Atherosclerosis XII. Elsevier, Amsterdam, p 278

43. Berglund L, Wiklund O, Eggertsen G, Olofsson S-O, Eriksson M, Lindén T, Bondjers G, Angelin B 1993 Apolipoprotein E phenotypes in familial hypercholesterolemia: importance for expression of disease and response to therapy. J Intern Med 233:173178

44. De Knijff P, Stalenhoef AF, Mol MJ, Gevers Leuven JA, Smit J, Erkelens DW, Schouten J, Frants RR, Havekes LM 1990 The influence of apoE polymorphism on the response to simvastatin treatment in patients with heterozygous familial hypercholesterolemia. Atherosclerosis 83:89-97

45. Sijbrands EJG, Lombardi MP, Westendorp RGJ, Gevers Leuven JA, Meinders AE, Van der Laarse A, Frants RR, Havekes LM, Smelt AHM 1998 Similar response to simvastatin in patients heterozygous for familial hypercholesterolemia with mRNA negative and mRNA positive mutations. Atherosclerosis 136:247-254

46. Ferrieres B, Lambert B, Lussier-Cacan S, Davignon D 1995 Coronary artery disease in heterozygous familial hypercholesterolemia patients with the same LDL receptor gene mutation. Circulation 92:290-295

47. Gerdes LU, Gerdes C, Kervinen K, Savolainen M, Klausen IC, Hansen PS, Kesämiemi YA, Færgeman O 2000 The apolipoprotein $\epsilon 4$ allele determines prognosis and the effect on prognosis of simvastatin in survivors of myocardial infarction Circulation 101:1366-1371 